\title{
Co-occurrence of sequential and practice effects in the Simon task: Evidence for two independent mechanisms affecting response selection
}

\author{
Cristina IANi ANd Sandro Rubichi \\ University of Modena and Reggio Emilia, Reggio Emilia, Italy \\ ELENA GHERRI \\ Birkbeck College, University of London, London, England \\ AND \\ ROBERTO NICOLETTI \\ University of Bologna, Bologna, Italy
}

\begin{abstract}
The Simon effect refers to the observation that responses to a relevant stimulus dimension are faster and more accurate when the stimulus and response spatially correspond than when they do not, even though stimulus position is irrelevant. Recent findings have suggested that the Simon effect can be strongly modulated by prior practice with a spatially incompatible mapping and by correspondence sequence. Although practice is thought to influence conditional stimulus-response $(\mathrm{S}-\mathrm{R})$ processing, leaving response priming through the unconditional route unaffected, sequential effects are thought to represent trial-by-trial adaptations that selectively involve unconditional S-R processing. In the present study, we tested this assumption by assessing the effects of correspondence sequence both when the Simon task alone was performed and when it was preceded by a spatial compatibility task with either incompatible (Experiments 1-2) or compatible (Experiment 2) instructions. The observation that practice and correspondence sequence co-occur and exert additive effects strongly demonstrates that the two factors affect different processing routes.
\end{abstract}

A human observer responds more efficiently to stimuli with a spatially corresponding response than with a spatially noncorresponding response, even if the location of the stimuli is irrelevant to the performance of the task and the response has to be emitted on the basis of a nonspatial stimulus feature (e.g., color or shape). For instance, if participants are required to press a left key in response to a red square and a right key in response to a green square, responses will be faster when the red square appears on the left than when it appears on the right. The influence of the irrelevant spatial stimulus feature on performance is known as the Simon effect (Simon \& Rudell, 1967; for reviews, see Hommel \& Prinz, 1997; Proctor \& Vu, 2006), and it is believed to be the result of the interaction between two parallel and independent processing routes connecting perception to action (see, e.g., De Jong, Liang, \& Lauber, 1994; Kornblum, 1994): an indirect route, called "conditional," and a direct route, called "unconditional." According to Barber and O’Leary (1997; see also Umiltà \& Zorzi, 1997), the two processing routes rely on different memory associations connecting stimulus and response.

When a stimulus appears, the conditional route activates the required response on the basis of task-defined associations that connect a stimulus to a specific response. These associations are established by instructions and are supposed to be short-lived. The unconditional route activates the response that spatially corresponds to the stimulus location through preexisting stimulus-response (S-R) associations, which are independent from instructions. These associations are supposed to be either determined genetically or overlearned as a result of extensive practice (Umiltà \& Zorzi, 1997). When the two activated responses correspond, no competition arises; rather, the redundancy of the same response code might generate a facilitation effect (Umiltà, Rubichi, \& Nicoletti, 1999). When they are different, however, the incorrect response needs to be aborted, thus causing a slowing of response time and an increased number of errors.

The Simon effect has proven to be a robust phenomenon whose magnitude can be reduced only partially through practice (see, e.g., Proctor \& Lu, 1999; Simon, Craft, \& Webster, 1973). Recent findings suggest that it can be strongly modulated by prior experience, however, at both a between- and a within-tasks level.

When we consider the between-tasks level, we refer to the studies that have assessed the Simon effect as a function

C. Iani, cristina.iani@unimore.it 
of practice in a different task that was performed immediately before the Simon task (practice effects). These studies have indicated that practicing with an incompatible spatial mapping (e.g., responding to the left stimulus with the right key and vice versa) before performing a Simon task can eliminate (Tagliabue, Zorzi, Umiltà, \& Bassignani, 2000) or even reverse the Simon effect (Proctor \& Lu, 1999). This modulation occurs not only when stimuli in the two tasks are visual, but also when stimuli in the spatial compatibility task are auditory and stimuli in the Simon task are visual (Tagliabue, Zorzi, \& Umiltà, 2002) and, with extensive practice, when stimulus and response in the two tasks vary orthogonally along the horizontal and vertical dimensions (Vu, 2007). In contrast, practicing with a spatially compatible mapping does not affect the Simon effect.

At a within-tasks level, the Simon effect is reversed when location-relevant trials with an incompatible mapping are intermixed with location-irrelevant trials in the same task (Marble \& Proctor, 2000; Proctor, Marble, \& $\mathrm{Vu}, 2000)$. It is also reversed when noncorresponding trials are $80 \%$ of the total trials (Hommel, 1994), but it increases when corresponding trials predominate (Toth et al., 1995). When there are an equal number of corresponding and noncorresponding trials, the Simon effect has been shown to reduce (see, e.g., Praamstra, Kleine, \& Schnitzler, 1999; Ridderinkhof, 2002), disappear (see, e.g., Mordkoff, 1998; Stürmer, Leuthold, Soetens, Schröter, \& Sommer, 2002), or even reverse (di Pellegrino, Ciaramelli, \& Làdavas, 2007; Hommel, Proctor, \& Vu, 2004; Wendt, Kluwe, \& Peters, 2006) after a noncorresponding trial, whereas a regular effect is evident after a corresponding trial. The latter phenomena are referred to as sequential effects.

Taken together, these results suggest that the influence of irrelevant spatial information on performance is not as unavoidable as was once thought, but rather depends on the preceding experience and on the specific task context. Even though the majority of the accounts of betweentasks and within-tasks effects agree with this conclusion, there is disagreement regarding exactly how experience can influence performance.

To explain the elimination (and reversal) of the Simon effect after practice with an incompatible mapping, Tagliabue et al. (2000) introduced the notion of "long-lasting short-term links." According to their hypothesis, the short-term (task-related) association between a stimulus location and the incompatible response that was created in order to perform the spatial compatibility task remains active and influences performance in the subsequent Simon task. This may occur because, as suggested by Logan's (1988) automatization theory, if the same S-R mapping is repeatedly used, the $\mathrm{S}-\mathrm{R}$ association is stored into the memory. As a consequence, when a stimulus with a given spatial code occurs, the response that has been associated with it for repeated instances is retrieved automatically, irrespective of a change in task instructions. According to this view, practice is not supposed to affect the long-term associations, which are considered unmodifiable.

Note that, if one assumes that the presence of a higher number of noncorresponding trials establishes a preferential noncorresponding S-R association through short- term links, the same mechanism may explain the effects of correspondence frequency (cf. Stürmer et al., 2002).

A different mechanism is considered to be responsible for sequential effects. According to some researchers, these effects indicate that activation through long-term links, considered to be automatic, is instead influenced by top-down control processes (Mordkoff, 1998; Ridderinkhof, 2002; Stoffels, 1996; Stürmer et al., 2002), with compensatory adjustments taking place after the detection of a conflict in the current trial to avoid conflict in the following trial (e.g., Botvinick, Braver, Barch, Carter, \& Cohen, 2001). Such a view is supported by both electrophysiological (e.g., Gratton, Coles, \& Donchin, 1992; Stürmer \& Leuthold, 2003; Stürmer et al., 2002) and neuroimaging (e.g., Egner \& Hirsch, 2005) data. What is still a matter of debate is whether these adjustments entail a modulation of the flow of activation through the unconditional route, as suggested by Mordkoff, or a suppression of the route, as postulated by Stürmer et al. (2002).

Some researchers have questioned the idea that sequential modulations of the Simon effect reflect changes in cognitive control and instead have considered them to be the result of S-R priming (Mayr, Awh, \& Laurey, 2003) or binding effects (e.g., Hommel et al., 2004; Notebaert, Gevers, Verbruggen, \& Liefooghe, 2006; Notebaert, Soetens, \& Melis, 2001). Crucially, in the typical Simon task, correspondence sequence is confounded with the presence of stimulus and response repetitions in consecutive trials. More precisely, whereas sequences of two corresponding trials $(\mathrm{C}-\mathrm{C})$ and sequences of two noncorresponding trials (NC-NC) are either complete repetitions of stimulus position and response or complete changes of both stimulus position and response, mixed sequences $(\mathrm{C}-\mathrm{NC}$ or $\mathrm{NC}-\mathrm{C})$ are always partial repetitions in which either stimulus position or response repeats. Since responses to both complete repetitions and complete alternations are always faster than those to partial repetitions (Hommel, 1998, 2004; Hommel \& Colzato, 2004; Pashler \& Baylis, 1991), the Simon effect turns out to be larger after a corresponding trial ( $\mathrm{C}-\mathrm{C}$ and $\mathrm{C}-\mathrm{NC}$ trials), whereas it is smaller after a noncorresponding trial ( $\mathrm{NC}-\mathrm{C}$ and $\mathrm{NC}-\mathrm{NC})$. Hence, the advantage of correspondence-level repetition may be accounted for by the repetition of specific stimulus and response features, obviating the need to assume the intervention of a top-down control mechanism. If this account is true, sequential modulations of the Simon effect will disappear when stimulus and response repetitions are controlled. As some recent studies have suggested, however, this is not always the case (see, e.g., di Pellegrino et al., 2007; Stürmer et al., 2002; Ullsperger, Bylsma, \& Botvinick, 2005; Wühr \& Ansorge, 2005).

In summary, both practice and sequential effects are evidence of an adaptation to specific experiences by favoring a specific S-R link, irrespective of task goals. On one hand, practice and asymmetries in the frequency of noncorresponding trials are thought to affect the strength of short-term links, leaving response priming through the unconditional route unaffected. On the other hand, sequential effects are thought to represent trial-by-trial adaptations selectively involving unconditional S-R processing. 
Following the logic of the additive factors method (Sternberg, 1969), if practice and correspondence sequence influence different mechanisms (that is, the conditional and unconditional routes of processing, respectively) - as can be concluded on the basis of the accounts described above - then their effects on performance will be additive. Alternatively, an interaction between these factors would suggest the possibility that they exert their influence on the same mechanism (that is, both influence the activity of the same processing route); as a consequence, either the accounts of practice effects or those of sequential effects would need to be revised.

Two experiments were conducted to test these predictions. In both experiments, practice and correspondence sequence were concurrently manipulated. In Experiment 1 , half of the participants performed only the Simon task, whereas the other half transferred to the Simon task after practicing a spatial-compatibility task with an incompatible mapping. In Experiment 2, participants practiced with either a spatially incompatible mapping or a spatially compatible mapping before transferring to the Simon task. The orientation of the $\mathrm{S}-\mathrm{R}$ set during the compatible practice was either horizontal or vertical. This design allowed us to disentangle the specific, mapping-related effects of practice from the nonspecific effects.

\section{EXPERIMENT 1}

In Experiment 1, we assessed modulations of the Simon effect as induced by correspondence sequence when only the Simon task was performed or when it was performed after practice with a spatially incompatible S-R mapping. If correspondence sequence and prior practice affect the same mechanism, they will interact. If, as suggested by the accounts described above, they affect different mechanisms, they will exert additive effects.

Furthermore, to explore whether correspondence sequence effects could result from stimulus and response features repetition, we assessed sequential modulations before and after the exclusion of both complete repetitions (that is, repetitions of both stimulus position and response) and response repetitions (e.g., di Pellegrino et al., 2007; Wühr \& Ansorge, 2005).

\section{Method}

Participants. Thirty-two right-handed undergraduate students (20-32 years of age; 20 female and 12 male) with normal or corrected-to-normal vision participated in the experiment. Sixteen performed only a Simon task, whereas 16 practiced with a spatially compatible task with an incompatible S-R mapping and then transferred, after a 5-min interval, to the Simon task.

Apparatus and Stimuli. Participants sat in front of a color monitor that was controlled by an IBM computer, in a dimly illuminated room, and at a viewing distance of approximately $57 \mathrm{~cm}$. Stimulus presentation and response collection were controlled by the E-Prime software system. The stimuli were white, red, or green solid squares $\left(2^{\circ} \times 2^{\circ}\right)$, presented to the left or to the right of fixation with an eccentricity of $5^{\circ}$.

Responses were executed by pressing the "G" or the "L" key on the keyboard with the left or the right index finger, respectively. The keyboard was located centrally with respect to the body midline.
Procedure. In the practice session, the stimulus was white, and participants were asked to respond as quickly and accurately as possible to the left stimulus with the right response and to the right stimulus with the left response. The practice session consisted of 384 trials that were divided into four blocks of 96 trials each.

In the Simon task, participants were asked to respond as quickly and as accurately as possible to the color of the stimulus, ignoring its location. Half of the participants responded to the red square with the left hand and to the green square with the right hand, and the other half experienced the inverse mapping rule. The task consisted of 768 trials that were divided into eight blocks of 96 trials each, preceded by 32 practice trials. Each block was composed of 32 threetrial sequences in which the first trial was named $n-2$, the second trial was named $n-1$, and the third trial was named $n$. Since each of the trials could be either corresponding or noncorresponding, eight different sequences were used $(\mathrm{C}-\mathrm{C}-\mathrm{C}, \mathrm{C}-\mathrm{C}-N C, \mathrm{C}-\mathrm{NC}-\mathrm{C}$, $\mathrm{C}-\mathrm{NC}-N C, \mathrm{NC}-\mathrm{C}-C, \mathrm{NC}-\mathrm{C}-N C, \mathrm{NC}-\mathrm{NC}-C, \mathrm{NC}-\mathrm{NC}-N C$, with italics denoting trial $n$ ) and were repeated four times in each experimental block. In this way, trial $n$ was preceded by either a corresponding or a noncorresponding response with equal probability, as was trial $n-1$.

In both tasks, the stimulus remained present for $1 \mathrm{sec}$, or until a response was made. The trial terminated if the participant did not respond within $1 \mathrm{sec}$. Visual feedback on speed and accuracy was provided at the center of the screen for $500 \mathrm{msec}$. The intertrial interval was $1 \mathrm{sec}$.

\section{Results}

Only the data of the Simon task were analyzed. Late responses (reaction times [RTs] $>1,000 \mathrm{msec}$ ) averaged $0.08 \%$. Responses faster than $150 \mathrm{msec}$ were excluded from the analysis $(0.1 \%)$, as were incorrect responses and responses that were preceded by two incorrect responses $(6.7 \%)$.

Analysis of correspondence sequence. Mean RTs and arcsine-transformed error rates in trial $n$ were submitted to repeated measures ANOVAs with group (control vs. incompatible-practice group) as a between-subjects factor, and with trial $n-1$ correspondence and trial $n$ correspondence as within-subjects factors. When necessary, comparisons were performed using Bonferroni's test for multiple comparisons. The respective data are displayed in Figure $1 .{ }^{1}$

The RT analysis showed that responses were faster after a corresponding trial $(389 \mathrm{msec})$ than after a noncorresponding ( $395 \mathrm{msec})$ trial, as indicated by the significant main effect of trial $n-1$ correspondence $[F(1,30)=$ $\left.11.00, M S_{\mathrm{e}}=97, p<.01, \eta_{\mathrm{p}}^{2}=.27\right]$. Corresponding trials $(385 \mathrm{msec})$ were faster than noncorresponding trials (399 msec), as indicated by the significant main effect of correspondence on trial $n\left[F(1,30)=27.50, M S_{\mathrm{e}}=228\right.$, $\left.p<.001, \eta_{\mathrm{p}}^{2}=.48\right]$. This correspondence effect was modulated by prior practice, as indicated by the interaction between trial $n$ correspondence and group $[F(1,30)=44.99$, $\left.M S_{\mathrm{e}}=228, p<.001, \eta_{\mathrm{p}}^{2}=.60\right]$, and by correspondence sequence, as indicated by the interaction between trial $n$ correspondence and trial $n-1$ correspondence $[F(1,30)=$ $\left.162.67, M S_{\mathrm{e}}=218, p<.001, \eta_{\mathrm{p}}^{2}=.84\right]$. Most importantly for the present purposes, there was a significant three-way interaction between group, trial $n-1$ correspondence, and trial $n$ correspondence $\left[F(1,30)=4.69, M S_{\mathrm{e}}=218, p<\right.$ $\left..04, \eta_{\mathrm{p}}^{2}=.14\right]$. 

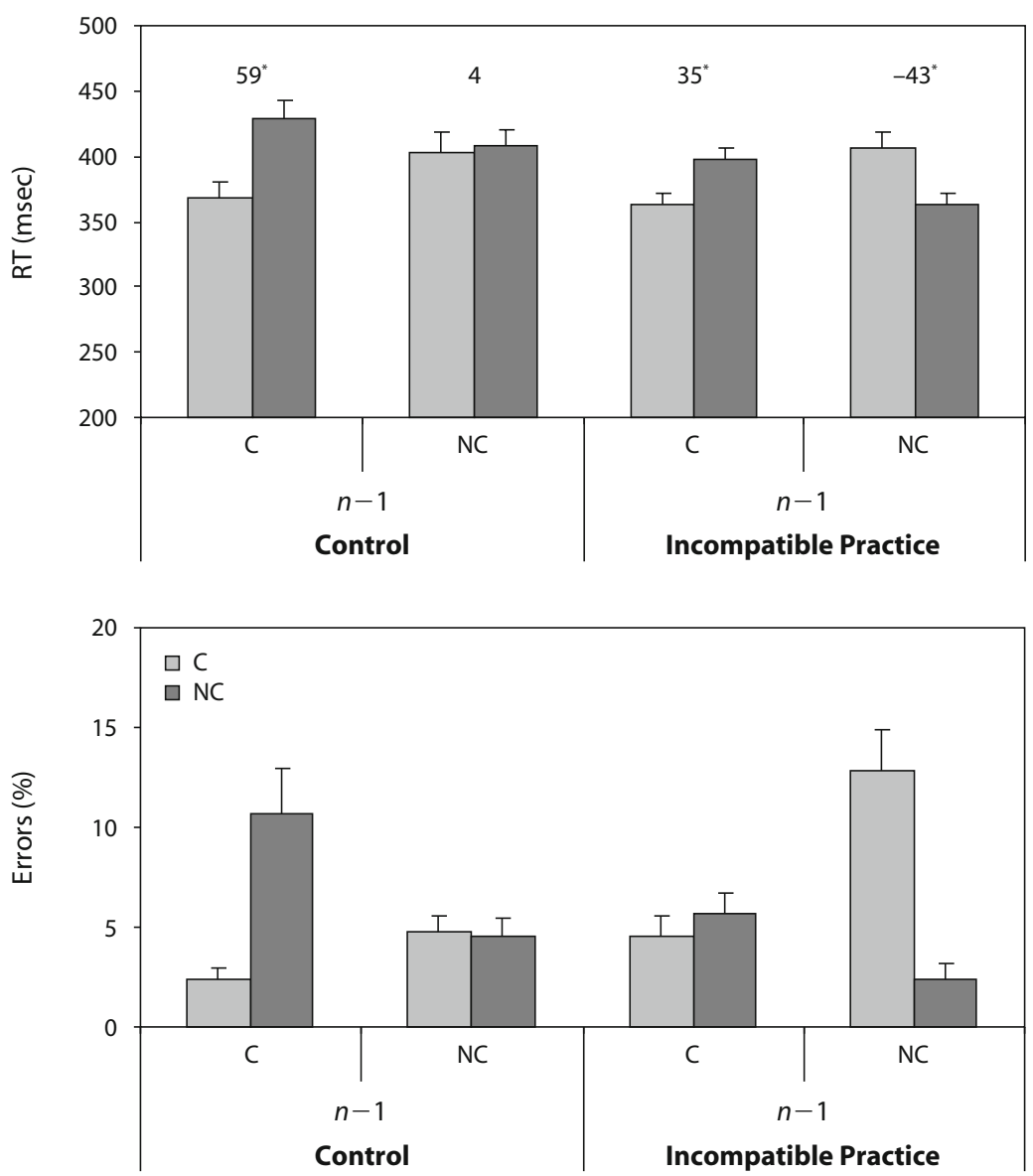

Figure 1. Mean reaction times (RTs, upper panel) and percentages of error (lower panel) for the current event in Experiment 1, as a function of practice group (control vs. incompatible practice) and preceding event (trial $n-1)$ correspondence. Error bars indicate standard errors of the mean. The magnitude of the Simon effect for separate conditions is reported on top. Asterisks denote significant values $(p<.05)$. C, corresponding; NC, noncorresponding.

After a corresponding trial $n-1$, the Simon effects were 59 and $35 \mathrm{msec}$ for the control and incompatible-practice groups, respectively. Pairwise comparisons showed that this difference was significant. After a noncorresponding trial $n-1$, no Simon effect was evident for the control group ( 4 msec, n.s.), but a 43 -msec reverse effect was evident for the incompatible-practice group. Pairwise comparisons showed that this difference was significant.

To better understand the three-way interaction, we ran separate ANOVAs on corresponding and noncorresponding trial $n \mathrm{~s}$. Corresponding responses did not differ between the two groups and were faster when trial $n-1$ was corresponding (366 msec) than when it was noncorresponding $(405 \mathrm{msec})\left[F(1,30)=116.32, M S_{\mathrm{e}}=210\right.$, $\left.p<.001, \eta_{\mathrm{p}}^{2}=.80\right]$. Noncorresponding responses were faster for the incompatible-practice group (381 msec) than for the control group $(418 \mathrm{msec})\left[F(1,30)=4.95, M S_{\mathrm{e}}=\right.$ $\left.4,462, p<.04, \eta_{\mathrm{p}}^{2}=.14\right]$, and they were faster when trial $n-1$ was noncorresponding $(385 \mathrm{msec})$ than when it was corresponding $(413 \mathrm{msec})\left[F(1,30)=115.13, M S_{\mathrm{e}}=\right.$
$105, p<.001, \eta_{\mathrm{p}}^{2}=.79$ ]. The latter difference was larger for the incompatible-practice group ( $34 \mathrm{msec}$ ) than for the control group $(21 \mathrm{msec})$, as indicated by the interaction between group and trial $n-1$ correspondence $[F(1,30)=$ 6.98, $\left.M S_{\mathrm{e}}=105, p<.02, \eta_{\mathrm{p}}^{2}=.19\right]$.

With regard to errors, the interaction between group and trial $n$ correspondence reached significance $[F(1,30)=$ $\left.36.53, M S_{\mathrm{e}}=0.009, p<.01, \eta_{\mathrm{p}}^{2}=.55\right]$. This was because the incompatible practice group showed a reverse Simon effect, with fewer errors in noncorresponding trials $(3.5 \%$ vs. $7.6 \%$ in the control group and $8.7 \%$ vs. $4.0 \%$ in the incompatible-practice group for corresponding and noncorresponding trials, respectively). There was also a significant interaction between trial $n$ correspondence and trial $n-1$ correspondence $\left[F(1,30)=81.01, M S_{\mathrm{e}}=0.005, p<.001\right.$, $\left.\eta_{\mathrm{p}}^{2}=.73\right]$. After a corresponding trial, there was a significant Simon effect $(5.3 \%)$, whereas a reverse effect was evident after a noncorresponding trial $(-4.7 \%)$. The interaction between group, trial $n$ correspondence, and trial $n-1$ correspondence did not reach significance $(p=.19)$. 
Analysis of stimulus and response feature sequence. Following Hommel et al. (2004), data were considered in terms of repetition or alternation of the response and the stimulus location in the current and preceding trial, and they were entered into a repeated measures ANOVA with practice group as a between-subjects factor and with correspondence of trial $n$, stimulus-location sequence (repetition vs. alternation), and response sequence (repetition vs. alternation) as within-subjects factors. The interaction between stimulus-location sequence and response sequence was significant $\left[F(1,30)=155.57, M S_{\mathrm{e}}=\right.$ $\left.457.82, p<.001, \eta_{\mathrm{p}}^{2}=.84\right]$, and it was modulated by group $\left[F(1,30)=4.33, M S_{\mathrm{e}}=457.82, p<.05, \eta_{\mathrm{p}}^{2}=.13\right]$. Separate analyses by group showed that the interaction between stimulus-location sequence and response sequence was significant for both groups. For the control group, response repetitions were $28 \mathrm{msec}$ faster when the stimulus position was repeated ( 383 vs. $411 \mathrm{msec}$ for total repetitions and response repetitions, respectively), whereas alternations of the response were $27 \mathrm{msec}$ faster when the stimulus location was alternated (393 vs. $420 \mathrm{msec}$ for total alternations and response alternations, respectively) $\left[F(1,15)=54.34, M S_{\mathrm{e}}=454.97, p<.001, \eta_{\mathrm{p}}^{2}=.78\right]$. For the incompatible-practice group, response repetitions were $38 \mathrm{msec}$ faster when the stimulus position was repeated (363 vs. $401 \mathrm{msec}$ for total repetitions and response repetitions, respectively), whereas alternations of the response were $39 \mathrm{msec}$ faster when the stimulus location was alternated ( $364 \mathrm{vs.} 403 \mathrm{msec}$ for total alternations and response alternations, respectively) $[F(1,15)=105.23$, $\left.M S_{\mathrm{e}}=460.68, p<.001, \eta_{\mathrm{p}}^{2}=.87\right]$.

Furthermore, the interaction among stimulus-location sequence, response sequence, and trial $n$ correspondence was significant $\left[F(1,30)=8.61, M S_{\mathrm{e}}=204.99, p<.01\right.$, $\left.\eta_{\mathrm{p}}^{2}=.22\right]$. Pairwise comparisons showed that the difference between corresponding and noncorresponding responses was significant after complete alternations $(26 \mathrm{msec})$ but not after complete repetitions $(12 \mathrm{msec})$ or after partial repetitions of either the response $(13 \mathrm{msec})$ or the stimulus position $(4 \mathrm{msec})$.

To exclude the possibility that the results from the correspondence-sequence analysis were due to repetitions, all sequences that involved complete repetitions (i.e., sequences in which both response and stimulus position were repeated) or partial repetitions (i.e., sequences in which the response was repeated but stimulus position changed) were excluded from the analysis. In this way, $50 \%$ of $\mathrm{C}-\mathrm{C}$ and $\mathrm{NC}-\mathrm{NC}$ sequences and $50 \%$ of $\mathrm{NC}-\mathrm{C}$ and $\mathrm{C}-\mathrm{NC}$ sequences were excluded. The remaining data were analyzed as a function of practice group and correspondence level in trial $n-1$ and trial $n$.

In line with the correspondence-sequence analysis, the interaction between trial $n-1$ and trial $n$ correspondence was significant $\left[F(1,30)=87.65, M S_{\mathrm{e}}=409.7, p<\right.$ $\left..001, \eta_{\mathrm{p}}^{2}=.75\right]$, indicating that a positive Simon effect (49 $\mathrm{msec})$ was present following a corresponding trial, whereas a reverse effect $(-18 \mathrm{msec})$ was evident following a noncorresponding trial. In contrast with the previous analysis, this interaction was not modulated by group $(p=.11)$.

\section{Discussion}

The results of Experiment 1 showed that the Simon effect was modulated by practice and by correspondence sequence. Interestingly, 384 practice trials with an incompatible mapping reversed the Simon effect in errors but not in RTs. Since the Simon task in the present study was longer than those in previous studies, we analyzed the Simon effect as a function of experimental block to exclude the possibility that transfer effects dissipated throughout the 768 -trial transfer session. The interaction between block and correspondence did not reach significance $(F<1)$, however, suggesting that only a very long practice session can reverse the overall effect on RTs.

At a within-tasks level, the Simon effect on RTs was modulated by the correspondence of the preceding trial in different ways for the two experimental groups. When the Simon task alone was performed, a large Simon effect $(59 \mathrm{msec})$ was evident following a corresponding trial, whereas it was eliminated following a noncorresponding trial. These results replicate those of previous studies (e.g., Stürmer et al., 2002) and support the idea that the detection of a conflict in trial $n-1$ triggers adaptations that are aimed at eliminating the impact of spatial S-R correspondence on response selection in the following trial. The observation that this pattern of results persisted even when exact stimulus and response repetitions were excluded from the analysis supports the idea that sequential modulations are not due simply to feature repetition and/or response-priming effects. Rather, these results, along with those of studies that used other conflict tasks - such as the Stroop (Kerns et al., 2004) and the flanker tasks (Botvinick, Cohen, \& Carter, 2004; Botvinick, Nystrom, Fissel, Carter, \& Cohen, 1999) - provide further support for the view that the automatic activation of the response corresponding to stimulus location is permeable to contextdependent influences.

The finding that the Simon effect for errors reversed after a noncorresponding trial suggests that these modulations may not act simply by suppressing the long-term corresponding associations but rather by changing the weight of both corresponding and noncorresponding S-R associations, favoring either one or the other depending on the corresponding level of the preceding trial. Indeed, the suppression of the automatic activation of a corresponding response can explain the absence of the Simon effect but not its reversal: Since the unconditional route is suppressed after a noncorresponding trial, a response would be selected solely on the basis of the relevant (nonspatial) stimulus dimension; hence, no advantage for corresponding responses would be evident. ${ }^{2}$

The spatially incompatible practice had no effect on corresponding RTs, which did not differ between the two groups and were faster than noncorresponding RTs when preceded by a corresponding event. It speeded up noncorresponding responses, however, thus leading to a reduced but still present 35-msec Simon effect following a corresponding event and resulting in a reverse effect $(-43 \mathrm{msec})$ following a noncorresponding event.

Interestingly, the interaction between practice and correspondence sequence, a result that contradicts the idea 
that the two factors affect different processing routes, did not reach statistical significance after removal of all response repetitions.

\section{EXPERIMENT 2}

At first glance, the results of Experiment 1 may be taken as an indication that practice and correspondence sequence influence the same mechanism, since a significant interaction (that is, a larger reversal of the effect following a noncorresponding trial for the incompatiblepractice group) was found. This finding should be taken with caution, however, since it was significant for RTs but not for errors, and it did not reach significance after controlling for the repetition of stimulus position and/or response.

A possible interpretation of this interaction is that it simply reflects a nonspecific effect of experimental practice. To address this issue, in Experiment 2 we compared three different practice conditions: a neutral practice with vertical S-R arrangement, an incompatible practice with horizontal S-R arrangement, and a compatible-practice condition with horizontal S-R arrangement. In this way, we could compare (1) situations in which either corresponding (compatible practice) or noncorresponding (incompatible practice) responses were favored by practice with (2) a situation in which neither one was favored (neutral practice), keeping task time constant. The latter condition was meant to replace the control condition of Experiment 1.

We chose as neutral practice a response-compatible task with vertical S-R arrangements, because betweendimension practice effects are evident only after a very large amount of practice and do not seem to depend on the retrieval during the transfer phase of the specific $\mathrm{S}-\mathrm{R}$ associations that are established to perform the practice task. Rather, they seem to be due to the acquisition of a "respond opposite" rule (Vu, 2007). By using this practice, therefore, we eliminated the possibility that the spatial mapping that was practiced before transferring to the Simon task influenced which response was automatically activated in response to stimulus location.

\section{Method}

Participants. Forty-eight new students (19-36 years of age; 34 female and 14 male), selected as in Experiment 1, participated in the experiment. Sixteen were randomly assigned to each of three practice conditions: horizontal incompatible mapping, horizontal compatible mapping, and vertical compatible mapping. After a 5-min interval, they all transferred to the Simon task.

Stimuli, Apparatus, and Procedure. The stimuli, apparatus, and procedure for the Simon task and for the horizontal incompatible practice were the same as those that have been described for Experiment 1 .

Stimuli for the horizontal and vertical compatible-practice conditions were solid white diamonds. In the horizontal compatiblepractice condition, stimuli could appear $5^{\circ}$ to the left or $5^{\circ}$ to the right of fixation, and participants were asked to respond to the left stimulus with the left response and to the right stimulus with the right response. Responses were executed by pressing the " $G$ " or the "L" key on the keyboard with the left or right index finger, respectively.
}

In the vertical compatible practice, stimuli could appear $5^{\circ}$ to the top or $5^{\circ}$ to the bottom of fixation, and participants were required to respond to the top stimulus with the upper key and to the bottom stimulus with the lower key. Responses were executed by pressing the " $\mathrm{M}$ " or the " $\mathrm{Z}$ " key on the keyboard, which was aligned vertically (the "Z" was at the top). Half of the participants pressed the "M" key with the left finger and the " $Z$ " key with the right finger in the first half of the task and switched fingers in the second half. The reverse order was used with the other half of the participants.

\section{Results}

Data were treated in the same manner as in Experiment 1 . Late responses (RT $>1,000 \mathrm{msec}$ ) averaged $0.3 \%$. Responses faster than $150 \mathrm{msec}$ averaged $0.4 \%$. Errors averaged $6.9 \%$.

Analysis of correspondence sequence. RTs and arcsine-transformed error rates were analyzed in the same manner as in Experiment 1. The respective data are displayed in Figure 2.

The RT analysis showed that the three practice groups did not differ $(405,397$, and $389 \mathrm{msec}$, for the incompatiblepractice, horizontal compatible-practice, and vertical compatible-practice conditions, respectively; $F<1$ ). Responses were faster after a corresponding trial $(394 \mathrm{msec})$ than after a noncorresponding trial $(400 \mathrm{msec})$, as indicated by the significant main effect of trial $n-1$ correspondence $\left[F(1,45)=9.52, M S_{\mathrm{e}}=208, p<.01, \eta_{\mathrm{p}}^{2}=\right.$ .17]. A regular Simon effect was evident in trial $n$, as indicated by a significant main effect of trial $n$ correspondence $\left[F(1,45)=21.55, M S_{\mathrm{e}}=432, p<.001, \eta_{\mathrm{p}}^{2}=.32\right]$, with faster RTs for corresponding trials $(390 \mathrm{msec})$ than for noncorresponding trials (404 msec).

The Simon effect was different for the three practice groups, as indicated by the significant interaction between trial $n$ correspondence and practice group $[F(1,45)=$ $\left.10.57, M S_{\mathrm{e}}=432, p<.001, \eta_{\mathrm{p}}^{2}=.32\right]$. Pairwise comparisons showed a positive effect for the horizontal (26-msec) and vertical (20-msec) compatible-practice groups, and no effect $(-5 \mathrm{msec}, \mathrm{n} . \mathrm{s}$.) for the incompatible-practice group. The effect did not differ for the two compatiblepractice conditions.

As in Experiment 1, we found sequential modulations of the Simon effect, as indicated by the significant interaction between trial $n-1$ correspondence and trial $n$ correspondence $\left[F(1,45)=217.91, M S_{\mathrm{e}}=276, p<.0001\right.$, $\left.\eta_{\mathrm{p}}^{2}=.83\right]$.

Pairwise comparisons showed that corresponding trials were $50 \mathrm{msec}$ faster than noncorresponding trials when trial $n-1$ was corresponding (369 vs. $419 \mathrm{msec}$ for corresponding and noncorresponding trials, respectively), whereas noncorresponding trials were $21 \mathrm{msec}$ faster than corresponding trials when trial $n-1$ was noncorresponding (411 vs. $390 \mathrm{msec}$ for corresponding and noncorresponding trials, respectively). The advantage for $\mathrm{C}-\mathrm{C}$ sequences over $\mathrm{NC}-\mathrm{C}$ sequences was significantly larger than the advantage for $\mathrm{NC}-\mathrm{NC}$ sequences over $\mathrm{C}-\mathrm{NC}$ sequences $\left[F(2,45)=217.64, M S_{\mathrm{e}}=553, p<\right.$ $\left..001, \eta_{\mathrm{p}}^{2}=.83\right]$.

In contrast to Experiment 1, the interaction between group, trial $n-1$ correspondence, and trial $n$ correspon- 

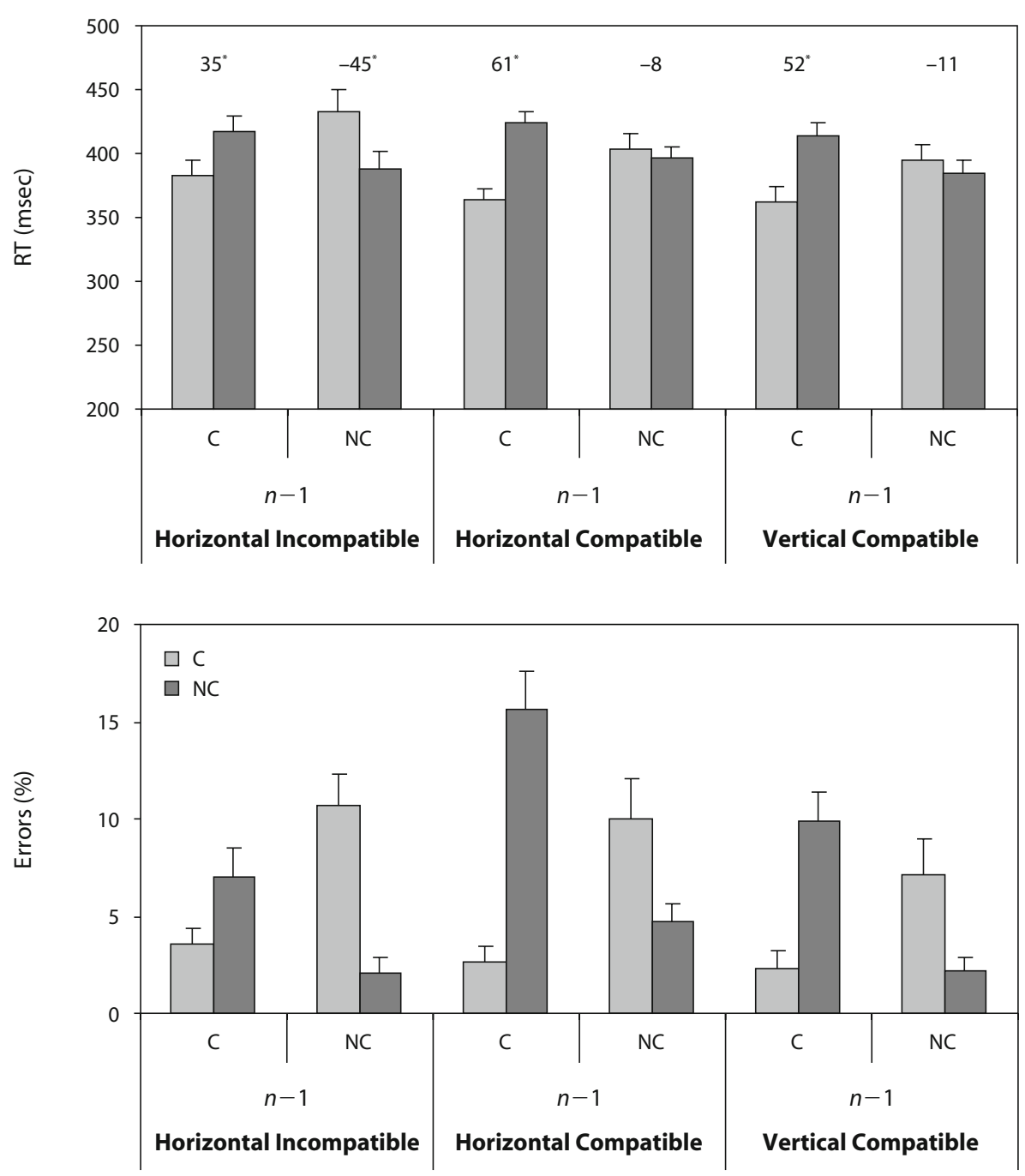

Figure 2. Mean reaction times (RTs, upper panel) and percentages of error (lower panel) for the current event in Experiment 2, as a function of practice group (horizontal incompatible practice vs. compatible practice with horizontal and vertical stimulus-response arrangements) and preceding event (trial $n-1)$ correspondence. Error bars indicate standard errors of the mean. The magnitude of the Simon effect for separate conditions is reported on top. Asterisks denote significant values $(p<.05)$. $\mathrm{C}$, corresponding; NC, noncorresponding.

dence did not reach significance $(p=.35)$, indicating that sequential effects were present for all three groups.

With regard to errors, we found a significant interaction between trial $n$ correspondence and practice group $\left[F(2,45)=9.85, M S_{\mathrm{e}}=0.01, p<.001, \eta_{\mathrm{p}}^{2}=.53\right]$, with a significant difference between corresponding $(6.3 \%)$ and noncorresponding trials $(10.2 \%)$ for only the horizontal compatible group. The interaction between trial $n-1$ correspondence and trial $n$ correspondence was significant $\left[F(1,45)=187.88, M S_{\mathrm{e}}=0.01, p<.001, \eta_{\mathrm{p}}^{2}=.99\right]$. Pairwise comparisons showed a positive Simon effect after corresponding trials $(7.9 \%)$ and a reverse effect after noncorresponding trials $(-6.3 \%)$. Such a pattern was evident irrespective of practice group, as indicated by the lack of a significant three-way interaction involving this factor $(F<1)$.

Analysis of stimulus and response feature sequence. The analysis of repetition and alternation of stimulus location and response showed a significant two-way interaction between location sequence and response sequence $\left[F(1,45)=207.34, M S_{\mathrm{e}}=583.83, p<.001, \eta_{\mathrm{p}}^{2}=.82\right]$, and a three-way interaction among location sequence, response sequence, and trial $n$ correspondence $[F(1,45)=$ 10.20, $\left.M S_{\mathrm{e}}=435.57, \eta_{\mathrm{p}}^{2}=.18\right]$. Pairwise comparisons showed a significant Simon effect after complete repetitions $(20 \mathrm{msec})$ and alternations $(22 \mathrm{msec})$. No effect was evident after partial repetitions of either the response $(9 \mathrm{msec})$ or the stimulus position $(5 \mathrm{msec})$. 
As before, the correspondence sequence analysis was performed after the exclusion of sequences including complete repetitions (i.e., sequences in which both response and stimulus position were repeated) or partial repetitions (i.e., sequences in which response was repeated but the stimulus position changed). We again found a significant interaction between trial $n-1$ and trial $n$ correspondence $\left[F(1,45)=89.26, M S_{\mathrm{e}}=553.52, p<.001, \eta_{\mathrm{p}}^{2}=.66\right]$ that was not further modulated by practice group $(F<1)$.

\section{Meta-Analyses}

To assess whether the incompatible-practice conditions that were used in the two experiments differ significantly, we performed a repeated measures ANOVA, using the magnitude of the Simon effect as a dependent variable, and with experimental condition as a between-subjects factor and trial $n-1$ correspondence (corresponding vs. noncorresponding) as a within-subjects factor. The analysis revealed a main effect of trial $n-1$ correspondence only $\left[F(1,30)=205.8, M S_{\mathrm{e}}=488.15, p<.001, \eta_{\mathrm{p}}^{2}=\right.$ .87]. Since neither the main effect of experimental condition nor the interaction with trial $n-1$ correspondence reached significance $(F \mathrm{~s}<1)$, we performed a second analysis to assess the differences among the control condition of Experiment 1 and the three practice conditions of Experiment 2 (incompatible, horizontal compatible, and vertical compatible).

We found a main effect of practice group $[F(3,60)=$ $\left.11.11, M S_{\mathrm{e}}=780.68, p<.001, \eta_{\mathrm{p}}^{2}=.36\right]$. Pairwise comparisons showed that the Simon effect that was evident in the incompatible-practice group $(-5 \mathrm{msec})$ differed significantly from the effects that were found for all other groups (control, $32 \mathrm{msec}$; horizontal compatible-practice, $26 \mathrm{msec}$; vertical compatible-practice, $21 \mathrm{msec}$ ). No difference was evident among the latter groups.

Trial $n-1$ correspondence was also significant $\left[F(1,60)=271.6, M S_{\mathrm{e}}=527.12, p<.001, \eta_{\mathrm{p}}^{2}=.82\right]$, with a $52-\mathrm{msec}$ Simon effect when trial $n-1$ was corresponding and a $15-\mathrm{msec}$ reverse effect when trial $n-1$ was noncorresponding. The interaction between practice group and correspondence sequence did not reach significance $[F(3,60)=1.72, p=.17]$.

\section{Discussion}

The purpose of Experiment 2 was to assess the specific effects of practice with a spatially incompatible mapping and to test whether the interaction between practice and correspondence sequence that had been found in Experiment 1 was still present when the number of practice trials for the different experimental conditions was equalized.

Similar to the findings for Experiment 1, we found both between-tasks and within-tasks modulations of the Simon effect. At a between-tasks level, our results showed that a spatially incompatible practice significantly eliminated the Simon effect in both RTs and errors, whereas a regular effect was evident after compatible practice with either horizontal or vertical S-R arrangements. At a within-tasks level, the Simon effect for both RTs and errors was modulated by correspondence sequence, with a positive Simon effect after a corresponding event and a reverse effect after a noncorresponding event. This modulation was present irrespective of practice group and, as suggested by control analyses, cannot be attributed to the repetition of stimulus position and/or response from one trial to the other.

It is important to note that practice and correspondence sequence did not interact, suggesting that when the nonspecific effect of practice is controlled for, the two factors do not have a synergic influence on performance but rather exert additive effects. Such a conclusion is supported also by the results of the meta-analyses that were performed on the data of the two experiments. Overall, even though the magnitude of the Simon effect was comparable when either no practice or compatible practice preceded the Simon task, it significantly decreased, approaching zero, after an incompatible practice. The effect of correspondence sequence added to the effect of incompatible practice, leading to a regular Simon effect (which was numerically smaller than the effect that was found for either the control or for either of the two compatible-practice conditions) after a corresponding event and resulting in an inverted effect after a noncorresponding event.

\section{GENERAL DISCUSSION}

We tested the hypothesis that the modulation of the Simon effect due to prior practice with a spatially incompatible mapping and that due to correspondence sequence result from two different mechanisms. Recent studies assessing these two effects in isolation have suggested that, although practice with a spatially incompatible mapping seems to affect conditional processing (see, e.g., Tagliabue et al., 2002; Tagliabue et al., 2000), correspondence sequence affects unconditional processing (see, e.g., Stürmer et al., 2002). We reasoned that if this hypothesis is true, the two factors would show additivity when concurrently manipulated. In contrast, if they affect the same processing route, they would show interactivity.

Our results showed concurrent effects of prior practice and correspondence sequence: The Simon effect was present after practice with a spatially compatible mapping (Experiment 2) but absent following a practice with a spatially incompatible mapping (Experiments 1-2); it was present following a corresponding trial but absent following a noncorresponding trial.

The most important result was that, when the amount of practice was controlled (Experiment 2), the two effects did not interact. Even though a spatially incompatible practice temporally strengthens noncorresponding $\mathrm{S}-\mathrm{R}$ links, leading to their automatic activation when a different task is performed, such an effect does not prevent the system from responding in a flexible way to trial-bytrial changes. Indeed, our results indicate that a single noncorresponding instance is sufficient to protect future performance from being negatively affected by the occurrence of another noncorresponding trial. As suggested by recent studies, two prefrontal areas - the anterior cingulate cortex (ACC) and the dorsolateral prefrontal cortex (DLPFC), which have been shown to be activated during performance in the Simon task (see, e.g., Kerns, 2006; Liu, Banich, Jacobson, \& Tanabe, 2004) - may be impli- 
cated in these trial-by-trial modulations. The activation of ACC following a conflict may serve as feedback to the DLPFC, which in turn may modulate response-selection processes by influencing response activation through the unconditional route. Support for this view comes from the observation that correspondence-sequence effects do not occur in patients with ACC lesions (di Pellegrino et al., 2007) or in individuals whose neural activity in the left DLPFC is interrupted by repetitive transcranial stimulation (Stürmer, Redlich, Irlbacher, \& Brandt, 2007).

The idea that sequential effects are independent from effects influencing conditional processing has received some support from studies that concurrently manipulated correspondence frequency and correspondence sequence (Marble \& Proctor, 2000; Stürmer et al., 2002). For instance, Marble and Proctor assessed modulations of the Simon effect as induced by correspondence frequency and correspondence sequence when location-irrelevant trials were intermixed with location-relevant trials, using either a spatially compatible mapping or a spatially incompatible mapping. In contrast to the present study, however, their experimental paradigm did not allow for the analytical estimation of the degree to which conditional and unconditional processing contributed to the observed performance, for several reasons. First, in the mixed conditions (in which location-relevant and location-irrelevant trials were intermixed), participants were required to switch from one task to the other, which may have changed the type of top-down control that was exerted on the task. As a consequence, both the enhanced Simon effect that was found when the mapping for the location-relevant trials was compatible and the reverse effect that was found when the mapping was incompatible could not be attributed solely to the effect of conditional, task-defined associations. Indeed, since there appeared to be no activation of the unconditional route, it is plausible to believe that the manipulation influenced unconditional processing, too, as suggested by the lack of a spatial compatibility effect for the location-relevant trials.

Second, correspondence frequency was indirectly manipulated. Since it has been shown that correspondence frequency influences conditional processing (see, e.g., Stürmer et al., 2002), one would expect its effects to interact in a synergic way with the effect of mixing locationrelevant and location-irrelevant trials. If this is the case, the effect that is obtained by intermixing tasks may be due to the bias that is induced by relative frequency and by the automatic application of the mapping rule that is in effect for the location-relevant trials, in addition to the influence on unconditional processing that is exerted by the taskswitching procedure. Finally, some considerations should be made regarding the fact that when correspondence sequence is assessed in a post hoc manner-as it was in Marble and Proctor's (2000) study, in which trial order was random - it is not possible to check for the equiprobable occurrence of all corresponding sequences (i.e., $\mathrm{C}-\mathrm{C}, \mathrm{NC}-\mathrm{C}, \mathrm{C}-\mathrm{NC}$, and $\mathrm{NC}-\mathrm{NC}$ ), with some sequence types being more frequent than others. If this is the case, correspondence sequence may be confounded with repetition of specific stimulus and response features. All of the above reasons may explain why the effects that were found in these studies were numerically larger than the effects that we found in the present study.

In conclusion, we found evidence that practice and correspondence sequence selectively affect the conditional and unconditional processing routes that connect perception to action. A spatially incompatible practice that is performed before a Simon task sets up the system by creating a new S-R association that contrasts with the preexisting S-R corresponding links. Such a setup affects conditional route processing and leaves response activation through the unconditional route unaffected, as suggested by the occurrence of sequential modulations of the Simon effect.

\section{AUTHOR NOTE}

We thank Michael Kane and three anonymous reviewers for useful comments on an earlier version of this article. We also thank Giulia Baroni and Nadia Milanese for helping with data collection for Experiment 2. Correspondence concerning this article should be sent to C. Iani, Dipartimento di Scienze Sociali, Cognitive e Quantitative, Università di Modena e Reggio Emilia, Via Allegri 9, 42100 Reggio Emilia, Italy (e-mail: cristina.iani@unimore.it).

\section{REFERENCES}

BARBER, P., \& O'LEARY, M. (1997). The relevance of salience: Towards an activational account of irrelevant stimulus-response compatibility effects. In B. Hommel \& W. Prinz (Eds.), Theoretical issues in stimulus-response compatibility (pp. 135-172). Amsterdam: NorthHolland.

Botvinick, M. M., Braver, T. S., Barch, D. M., Carter, C. S., \& Cohen, J. D. (2001). Conflict monitoring and cognitive control. Psychological Review, 108, 624-652.

Botvinick, M. M., Cohen, J. D., \& Carter, C. S. (2004). Conflict monitoring and anterior cingulate cortex: An update. Trends in Cognitive Sciences, 8, 539-546.

Botvinick, M. [M.], Nystrom, L. E., Fissel, K., Carter, C. S., \& Cohen, J. D. (1999). Conflict monitoring versus selection-for-action in anterior cingulate cortex. Nature, 402, 179-181.

De Jong, R., Liang, C.-C., \& Lauber, E. (1994). Conditional and unconditional automaticity: A dual-process model of effects of spatial stimulus-response correspondence. Journal of Experimental Psychology: Human Perception \& Performance, 20, 731-750.

di Pellegrino, G., Ciaramelli, E., \& LÀdavas, E. (2007). The regulation of cognitive control following rostral anterior cingulate cortex lesions in humans. Journal of Cognitive Neuroscience, 19, 275-286.

EgNER, T., \& Hirsch, J. (2005). Cognitive control mechanisms resolve conflict through cortical amplification of task-relevant information. Nature Neuroscience, 8, 1784-1790.

Gratton, G., Coles, M. G. [H.], \& Donchin, E. (1992). Optimizing the use of information: Strategic control of activation of responses. Journal of Experimental Psychology: General, 121, 480-506.

Hommel, B. (1994). Spontaneous decay of response-code activation. Psychological Research, 56, 261-268.

Hommel, B. (1998). Event files: Evidence for automatic integration of stimulus-response episodes. Visual Cognition, 5, 183-216.

Hommel, B. (2004). Event files: Feature binding in and across perception and action. Trends in Cognitive Sciences, 8, 494-500.

Hommel, B., \& Colzato, L. (2004). Visual attention and the temporal dynamics of feature integration. Visual Cognition, 11, 483-521.

Hommel, B., \& PrInZ, W. (EDS.) (1997). Theoretical issues in stimulusresponse compatibility. Amsterdam: North-Holland.

Hommel, B., Proctor, R. W., \& Vu, K.-P. L. (2004). A featureintegration account of sequential effects in the Simon task. Psychological Research, 68, 1-17.

KERNS, J. G. (2006). Anterior cingulate and prefrontal cortex activity in an FMRI study of trial-to-trial adjustments on the Simon task. NeuroImage, 33, 399-405.

Kerns, J. G., Cohen, J. D., MacDonald, A. W., III, Cho, R. Y., 
Stenger, V. A., \& CARTer, C. S. (2004). Anterior cingulate conflict monitoring and adjustments in control. Science, 303, 1023-1026.

Kornblum, S. (1994). The way irrelevant dimensions are processed depends on what they overlap with: The case of Stroop- and Simon-like stimuli. Psychological Research, 56, 130-135.

LiU, X., Banich, M. T., Jacobson, B. L., \& Tanabe, J. L. (2004). Common and distinct neural substrates of attentional control in an integrated Simon and spatial Stroop task as assessed by event-related fMRI. NeuroImage, 22, 1097-1106.

Logan, G. D. (1988). Toward an instance theory of automatization. Psychological Review, 95, 492-527.

Marble, J. G., \& Proctor, R. W. (2000). Mixing location-relevant and location-irrelevant choice-reaction tasks: Influences of location mapping on the Simon effect. Journal of Experimental Psychology: Human Perception \& Performance, 26, 1515-1533.

Mayr, U., Awh, E., \& LaUrey, P. (2003). Conflict adaptation effects in the absence of executive control. Nature Neuroscience, 6 , 450-452.

MoRDKOFF, J. T. (1998). The gating of irrelevant information in selectiveattention tasks. Abstracts of the Psychonomic Society, 3, 21.

Notebaert, W., Gevers, W., Verbruggen, F., \& Liefooghe, B. (2006). Top-down and bottom-up sequential modulations of congruency effects. Psychonomic Bulletin \& Review, 13, 112-117.

Notebaert, W., Soetens, E., \& Melis, A. (2001). Sequential analysis of a Simon task-Evidence for an attention-shift account. Psychological Research, 65, 170-184.

Pashler, H., \& BaYlis, G. C. (1991). Procedural learning: II. Intertrial repetition effects in speeded-choice tasks. Journal of Experimental Psychology: Learning, Memory, \& Cognition, 17, 33-48.

Praamstra, P., Kleine, B. U., \& Schnitzler, A. (1999). Magnetic stimulation of the dorsal premotor cortex modulates the Simon effect. NeuroReport, 10, 3671-3674.

Proctor, R. W., \& Lu, C.-H. (1999). Processing irrelevant location information: Practice and transfer effects in choice-reaction tasks. Memory \& Cognition, 27, 63-77.

Proctor, R. W., Marble, J. G., \& VU, K.-P. [L.] (2000). Mixing incompatible mapped location-relevant trials with location-irrelevant trials: Effects of stimulus mode on the reverse Simon effect. Psychological Research, 64, 11-24.

Proctor, R. W., \& VU, K.-P. L. (2006). Stimulus-response compatibility principle: Data, theory, and application. Boca Raton, FL: Taylor \& Francis.

RIDDERINKHOF, K. R. (2002). Activation and suppression in conflict tasks: Empirical clarification through distributional analyses. In W. Prinz \& B. Hommel (Eds.), Attention and performance XIX: Common mechanisms in perception and action (pp. 494-519). Oxford: Oxford University Press.

Simon, J. R., Craft, J. L., \& Webster, J. B. (1973). Reactions toward the stimulus source: Analysis of correct responses and errors over a five-day period. Journal of Experimental Psychology, 101, 175-178.

Simon, J. R., \& Rudell, A. P. (1967). Auditory S-R compatibility: The effect of an irrelevant cue on information processing. Journal of Applied Psychology, 51, 300-304.

SternberG, S. (1969). The discovery of processing stages: Extensions of Donders' method. In W. G. Koster (Ed.), Acta Psychologica, 30, 276-315. Amsterdam: North-Holland.

Stoffels, E. J. (1996). Uncertainty and processing routes in the selection of a response: An S-R compatibility study. Acta Psychologica, 94, 227-252.

Stürmer, B., \& Leuthold, H. (2003). Control over response priming in visuomotor processing: A lateralized event-related potential study. Experimental Brain Research, 153, 35-44.

Stürmer, B., Leuthold, H., Soetens, E., Schröter, H., \& SomMER, W. (2002). Control over location-based response activation in the Simon task: Behavioral and electrophysiological evidence. Journal of Experimental Psychology: Human Perception \& Performance, 28, 1345-1363.

Stürmer, B., Redlich, M., Irlbacher, K., \& Brandt, S. (2007).
Executive control over response priming and conflict: A transcranial magnetic stimulation study. Experimental Brain Research, 183, 329-339.

Tagliabue, M., Zorzi, M., \& Umiltà, C. (2002). Cross-modal remapping influences the Simon effect. Memory \& Cognition, 30, $18-23$.

Tagliabue, M., Zorzi, M., Umiltà, C., \& Bassignani, F. (2000). The role of long-term-memory and short-term-memory links in the Simon effect. Journal of Experimental Psychology: Human Perception \& Performance, 26, 648-670.

Toth, J. P., Levine, B., Stuss, D. T., OH, A., Winocur, G., \& MeiRAN, N. (1995). Dissociation of processes underlying spatial S-R compatibility: Evidence for the independent influence of what and where. Consciousness \& Cognition, 4, 483-501.

Ullsperger, M., Bylsma, L. M., \& Botvinick, M. M. (2005). The conflict adaptation effect: It's not just priming. Cognitive, Affective, \& Behavioral Neuroscience, 5, 467-472.

Umiltà, C. [A.], Rubichi, S., \& Nicoletti, R. (1999). Facilitation and interference components in the Simon effect. Archives Italiennes de Biologie, 137, 139-149.

Umiltà, C. A., \& ZoRZI, M. (1997). Commentary on Barber and O'Leary: Learning and attention in S-R compatibility. In B. Hommel \& W. Prinz (Eds.), Theoretical issues in stimulus-response compatibility (pp. 173-178). Amsterdam: North-Holland.

Vallesi, A., Mapelli, D., Schiff, S., Amodio, P., \& Umiltà, C. (2005). Horizontal and vertical Simon effect: Different underlying mechanisms? Cognition, 96, B33-B43.

VU, K.-P. L. (2007). Influences on the Simon effect of prior practice with spatially incompatible mappings: Transfer within and between horizontal and vertical dimensions. Memory \& Cognition, 35, 1463-1471.

Wendt, M., Kluwe, R. H., \& Peters, A. (2006). Sequential modulations of interference evoked by processing task-irrelevant stimulus features. Journal of Experimental Psychology: Human Perception \& Performance, 32, 644-667.

Wiegand, K., \& WASCher, E. (2005). Dynamic aspects of stimulusresponse correspondence: Evidence for two mechanisms involved in the Simon effect. Journal of Experimental Psychology: Human Perception \& Performance, 31, 453-464.

WÜHR, P., \& ANSORGE, U. (2005). Exploring trial-by-trial modulations of the Simon effect. Quarterly Journal of Experimental Psychology, 58A, 705-731.

\section{NOTES}

1. The experiment was originally designed to assess changes in the effect of irrelevant spatial information in the current trial (i.e., trial $n$ ) as a function of correspondence levels in trials $n-1$ (first-order correspondence effects) and $n-2$ (second-order correspondence effects). Consistent with previous studies (Stürmer et al., 2002; Wendt et al., 2006), second-order correspondence sequence did not reliably modulate the observed pattern of results; therefore, we report only the analyses of first-order effects.

2. Evidence in favor of the suppression hypothesis comes mostly from studies using vertically arranged S-R sets (e.g., Stürmer \& Leuthold, 2003; Stürmer et al., 2002; Stürmer, Redlich, Irlbacher, \& Brandt, 2007). Although the Simon effect that arises with horizontal S-R sets may be explained by visuomotor facilitation - that is, the automatic activation of the corresponding response - the Simon effect that arises with vertical S-R sets is thought be the result of cognitive interference- that is, the interference between the cognitive representations of stimulus and response spatial codes (see, e.g., Vallesi, Mapelli, Schiff, Amodio, \& Umiltà, 2005; Wiegand \& Wascher, 2005). In the vertical Simon task, therefore, inhibition of the unconditional component is not evident, because this component may not play any role.

(Manuscript received August 25, 2007; revision accepted for publication December 4, 2008.) 